\title{
Comparative evaluation of different marketed products of ciprofloxacin tablets in vitro
}

\author{
Mus'ab M. Khala*f, Hiyam A Al-Taii**, Imad A-J Thanoon*** \\ *Department of Clinical Pharmacy, College of Pharmacy, ${ }^{* *}$ Department of Biology, College of Sciences, . \\ ${ }^{* * *}$ Department of Pharmacology, College of Medicine, University of Mosul, Iraq
}

\begin{abstract}
The contents of four ciprofloxacin tablets products available in the private pharmacies of Mosul city were measured according to the British Pharmacopoeia (BP). Some biopharmaceutical parameters such as content uniformity, disintegration, and hardness were also measured for the same products. In addition, the antibacterial activity of these four products were assessed by microbiological assay on different types of gram negative bacteria in vitro.

The results indicated that there is a little differences in the content uniformity of these products and they are within acceptable requirement of BP and United State Pharmacopoeia (USP). In the same manner, the weight variation, disintegration, and hardness were within acceptable range according to the BP and USP. The microbiological assay indicated that these different products produce approximately the same inhibition zones on the same bacterial type.
\end{abstract}

The above results may be useful to predict the bioavailability of these different products .

الخلاصة

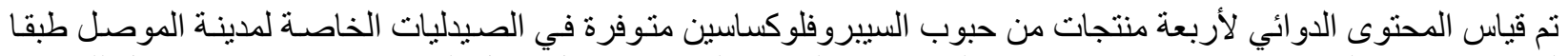

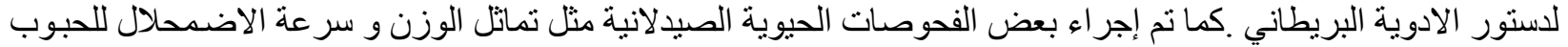

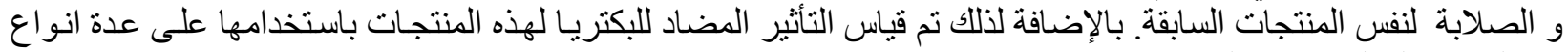

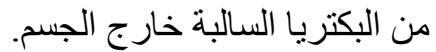

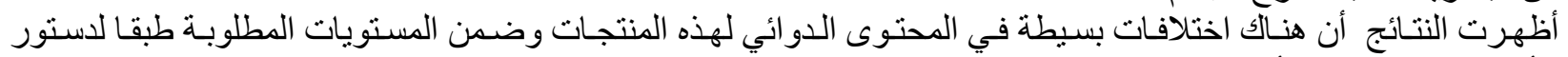

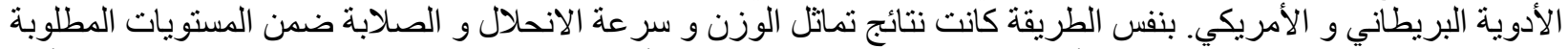

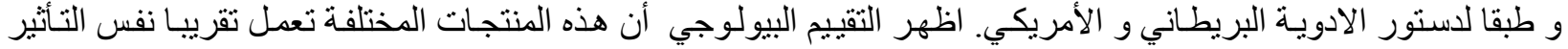

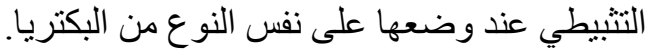
كذلك فالنتائج السابقة ربما هي مفيدة لتوقع التو افر الحيويا. لنيوي لهذه المنتجات المختلفة .

I nfectious diseases remain a constant threat to human and animal's health throughout the world. Antibiotics play a significant role to control the infectious diseases and they are one of the extensively used drugs throughout the world but more so in the developing countries'.

Ciprofloxacin is one of the fluoroquinolones antibacterial drugs, originally developed because of their excellent activity against gram negative aerobic bacteria (Enterobacteriacae, pseudomonas, neisseria, haemophilus, and campylobacter ${ }^{r}$. It has less activity against gram positive bacteria such as Streptococcus pneumoniae and Enterococcus faecalis. Chlamydia and mycoplasma are sensitive but anaerobes are not. Ciprofloxacin is bactericidal and exhibit concentration-dependent bacterial killingr.

There are several generic products of ciprofloxacin tablets in the pharmacies of Mosul city.

To reduce the cost of medicines especially for the low income group of developing countries, the World Health Organization (WHO) has continuously advocated the use of generic brands but this approach has not provided sufficient evidence for the substitution of one brand for another." 
The difference in cost between a branded and generic medicines may be as high as $9 . \%$. However, this substitution has been accompanied by a variety of problems. Therefore, routine laboratory testing of drugs in the market is crucial to protect public health especially in developing countries where counterfeit and substandard drugs have become a major challenge to health care services.

Post-market surveillance or monitoring involves all activities undertaken to obtain more data and information about a product after it had been granted marketing authorization and made available for public use. The data and information so obtained could be employed for product improvement, development of standards and regulations. It is therefore imperative to conduct post-market surveillance or monitoring of approved medicines in order to adequately assess the quality, therapeutic effectiveness and safety of medicines for the larger public. Postmarket monitoring ought not to be a one off event rather it should be a continuous event throughout the life of a drug product.

In Nigeria, chemical and biopharmaceutical inequivalencies have been reported for some brands of metronidazole tablets.

A study by Barone et el on ro generic products of piroxicam capsules showed that $\vee r \%$ of the brands failed to meet the USP requirements, several by a wide margin.

In a study conducted in Mosul city by Mus'ab et al $(r \ldots r)$ they found that two out of four products of carbamazepine tablets were bioinequivalent to brand name products.
Adegbolagun et al assess the content of ten generic product of ciprofloxacin tablets, they found that seven products gave values that conform to the USP specification of ciprofloxacin $\mathrm{HCl}$ content $(q \cdot-1) \cdot \%)$, while the remaining three products gave lower contents.

The need to select one product among several generic drug product of the same active ingredients during the course of therapy is a cause of concern to a health-care practitioner. The first stage in ascertaining the therapeutic equivalence of any drug product involves ascertaining the chemical and biopharmaceutical equivalency of such drug product. For antibiotics or antimicrobial agents, bioassay is also necessary for the assessment the quality of drugs.'

The aim of this study is to evaluate the four products of ciprofloxacin in term of chemical equivalence, biopharmaceutical equivalence and biological assessment of the active ingredient.

\section{Materials and methods Materials}

1- The samples of ciprofloxacin used is shown in table !.

r- Ciprofloxacin $\mathrm{HCl}$ standard powder was a gift from SDI company, Sammara, Iraq.

$r$ - Reagents used include $\cdot .1 \mathrm{~N} \mathrm{HCl}$, acetonitrile, orthophosphoric acid, and triethylamine.

₹- Isolates of bacteria such as Escherichia coli, Klebsiella pneumonia, Proteus and Salmonella species were obtained from microbiology department, College of sciences, University of Mosul.

Table 1: Samples of ciprofloxacin tablets

\begin{tabular}{|c|c|c|c|c|}
\hline Name of products & Name of company & Strength in mg & Batch number & Country of origin \\
\hline Bactiflox & Mepha & 0. & vorrr & Switzerland \\
\hline Dr-Reddy's & Dr-Reddy's laboratories & $0 \ldots$ & B $\vee \cdots \wedge$ & United kingdom \\
\hline Ceproz & Elsaad pharma & $0 \ldots$ & \& r cc & Syria \\
\hline Tyflox & Ajanta pharma limited & $0 \ldots$ & Ap $\cdots r \wedge k$ & India \\
\hline
\end{tabular}




\section{Methods}

\section{a. assay the content of tablets by HPLC method'}

1-Conditioning: stainless steel column( $(Y \circ \times \leq .7)$ packed with octadecylsilyl silica gel( $(\mathrm{i})$ ).

$r$ - The mobile phase is a mixture of $1 r$ volumes of acetonitril and $\Lambda V$ volumes of orthophosphoric acid at flow rate of $1.0 \mathrm{ml} /$ min and the $\mathrm{pH}$ of which has been adjusted to $r$ with triethylamine.

$r$-Detection wavelength of $r \vee \wedge \mathrm{nm}$.

\&-Maintain the temperature of the column at $\leqslant \cdot \dot{\mathrm{C}}$.

-Standard preparation: Weight exactly ro. mg of ciprofloxacin powder and dissolve in $1 \cdots \mathrm{ml}$ of mobile phase and sonic for $r \cdot$ minutes or until dissolve completely. Pipe $1 \mathrm{ml}$ and complete to $1 . \mathrm{ml}$ with mobile phase to obtain a solution with concentration of $\cdot$ ro $\mathrm{mg} / \mathrm{ml}$.

7-Test preparation: Weight a quantity of the powdered ciprofloxacin tablets equivalent to ro. mg of ciprofloxacin and put it in volumetric flask $(1 \cdots \mathrm{ml})$, add $v_{0} \mathrm{ml}$ of the mobile phase and mix for $r$. mins, then complete the volume to $1 \cdots \mathrm{ml}$ with mobile phase. Then filter throw filter paper (whatman) and take $1 \mathrm{ml}$ of the filtrate and complete to $1 \cdot \mathrm{ml}$ with mobile phase.

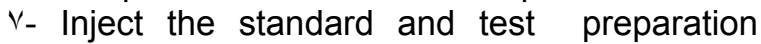
respectively.

A-Calculate the percent of ciprofloxacin in each tablets using the following formula.

$\%$ assay of ciprofloxacin content $=$ peak area of test product/ peak area of standard product x)...

\section{b. Uniformity of weight determination.}

Twenty tablets from each of the four brand was weighed individually using saturius balance. The average weights of the tablets were calculated as well as their deviation from the average weight were recorded. ${ }^{0,1 r}$

\section{c. Disintegration test}

Six tablets of each brands were employed for the test in a medium of $.1 \mathrm{~N} \mathrm{Hcl}$ at $r v \mathrm{C}$ in a disintegration apparatus (Pharma testGermany). The disintegration time was taken to be the time at which no particle remained on the basket of the system.

\section{d. Hardness test}

The crushing strength of a tablet (hardness) was determined with a tablet hardness tester (Pharma test, Germany). Four tablets were randomly selected from each brand and the pressure at which each tablets crushed was recorded in $\mathrm{kg} / \mathrm{cm}$. ${ }^{\mathrm{r}, \mathrm{O}, \mathrm{rr}}$

\section{e. Antimicrobial assay}

Kirby-Bauer method was used for this purpose ${ }^{r}$. The solutions of different products of ciprofloxacin (Bactiflox, Tyflox, Dr-Reddy's, and Ceproz) is prepared by dissolving these products in distilled water and according to concentrations applied by World Health Organization. Sterile filter paper discs were saturated with each of the solutions above and then applied to Mueller- Hinton agar overlaid with gram negative bacteria such as (Escherichia coli, Klebsiella pneumonia, Proteus and Salmonella). All plates were incubated at $r V \dot{c}$ for about $r \leqslant$ hours, then the diameter of each inhibition zone for each product is measured.

\section{Results}

a- HPLC method: The chromatogram after injection of standard and four products of ciprofloxacin into HPLC is shown in fig. $1, r, r, \varepsilon$ and 0 . The percent recovery of each brand of ciprofloxacin by HPLC method is within acceptable range as shown in table $r$.

Table $r$ : The percent recovery of ciprofloxacin tablets

\begin{tabular}{|c|c|}
\hline Name of product & Percent of content \\
\hline Bactiflox & $1.4 \%$ \\
\hline Dr-Reddy's & $1.1 .7 \%$ \\
\hline Ceproz & $1.1 . £ \%$ \\
\hline Tyflox & 9 9. $\% \%$ \\
\hline
\end{tabular}




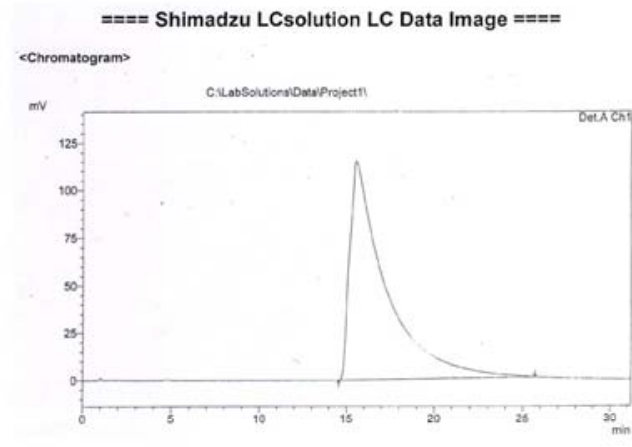

Fig 2 : Chromatogram of Bactiflox

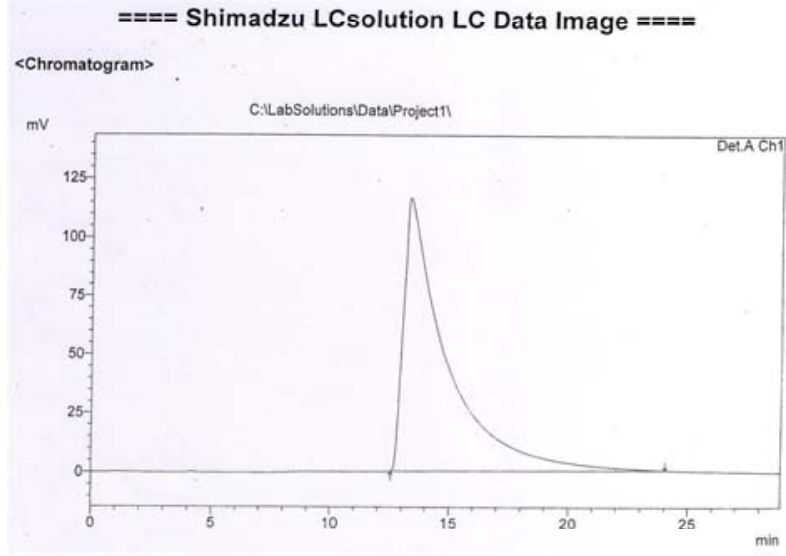

Fig 4 : Chromatogram of ceproz

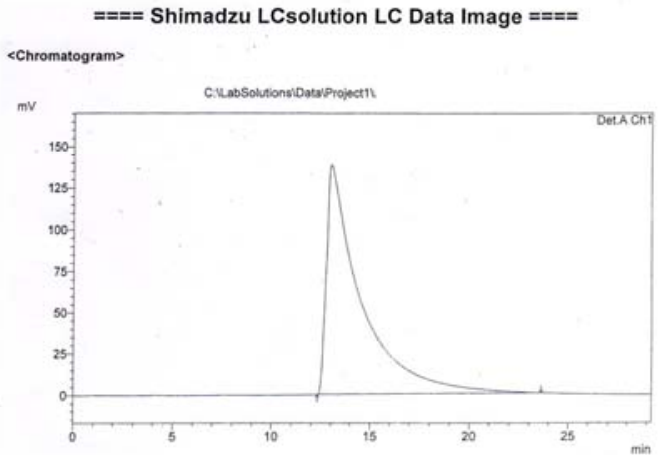

Fig 1: Chromatogram of Standard Ciprofloxacin

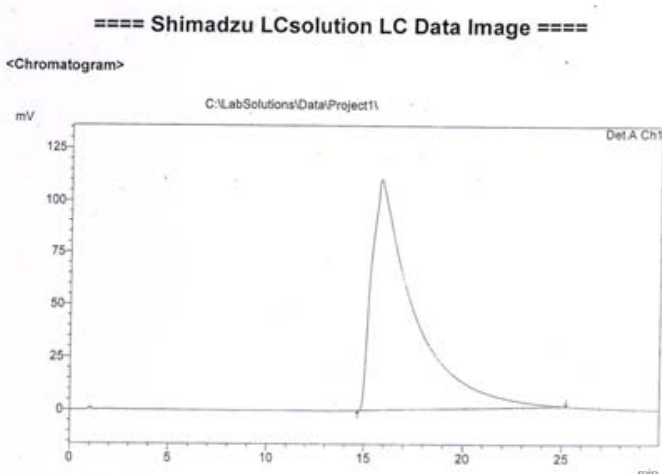

Fig 3 : Chromatogram of Dr_Reddy's

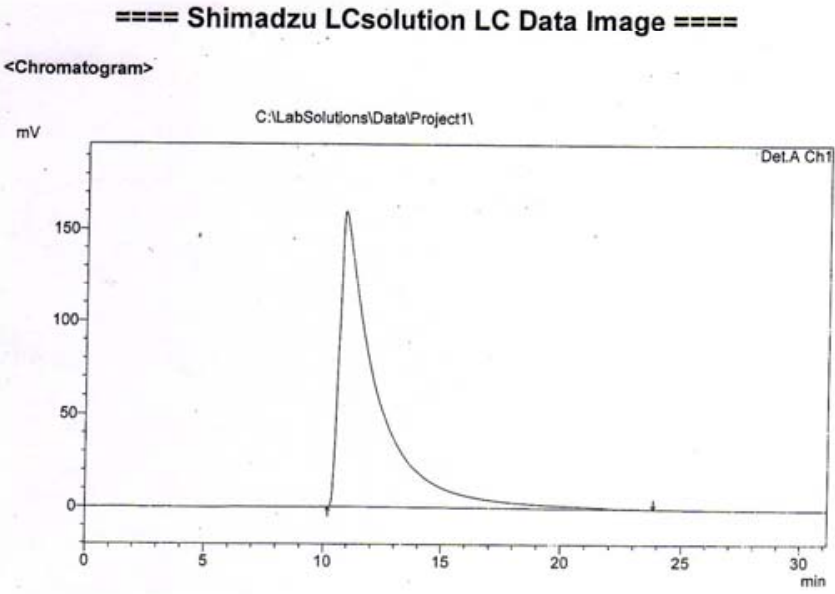

Fig 5: Chromatogram of Tyflox 
b. A summary of the result of average uniformity of weight, \% deviation from average weight, disintegration time, and hardness of four brands of ciprofloxacin tablets is shown in table $r$. c- Microbiological assay:. The result of microbiological assay shows that these different products produce approximately the same inhibition zone when applied separately on same bacterial type as shown in table $\varepsilon$.

Table r: Average uniformity of weight, \% deviation from average weight, disintegration time, and hardness of four brands of ciprofloxacin

\begin{tabular}{|c|c|c|c|c|}
\hline Brand name & $\begin{array}{l}\text { Average uniformity } \\
\text { of weight }(\mathrm{g})\end{array}$ & $\begin{array}{l}\% \text { Deviation from } \\
\text { average weight }\end{array}$ & $\begin{array}{c}\text { Average } \\
\text { disintegration (min) }\end{array}$ & $\begin{array}{l}\text { Average hardness } \\
\text { test } \mathrm{kg} / \mathrm{cm}^{r}\end{array}$ \\
\hline Bactiflox & $0 . \vee 4 \Lambda$ & $1 . r$ & ^.V & 11.1 \\
\hline Dr-Reddy's & $0 . \vee V \varepsilon$ & $<1$ & $\varepsilon .0$ & 17.4 \\
\hline Ceproz & $0.9 \mu \wedge$ & 1.0 & 0.1 & $1 \leqslant .9$ \\
\hline Tyflox & O.TNY & $<1$ & E. Yo & $10 . r$ \\
\hline
\end{tabular}

Table $\leqslant$ : The inhibition zone produce by different products of ciprofloxacin

\begin{tabular}{|c|c|c|c|c|}
\hline \multirow[t]{2}{*}{ Products } & \multicolumn{4}{|c|}{ Inhibition zone (mm) } \\
\hline & E. coli & Klebsiella p. & salmonella & Proteus \\
\hline Bactiflox & rA & rq & TV & TV \\
\hline Tyflox & TV & rA & $T \xi$ & $r$. \\
\hline Dr-Reddy's & rA & $r$. & ro & ro \\
\hline Ceproz & YY & ru & YY & ru \\
\hline
\end{tabular}




\section{Discussion}

The four tested products had ciprofloxacin HCL content within the acceptable range of USP and $\mathrm{BP}$ requirement. The highest amount of ciprofloxacin was found in Bactiflox which includes $1 . r \%$ of the labeled amount, whereas the lowest amount was found in Tyflox which includes $97 . £ \%$ of the labeled amount.

According to USP pharmacopoeia" ciprofloxacin tablets contain ciprofloxacin $\mathrm{HCL}$ equivalent to not less than $9 . \%$ and not more than $11 . \%$ of the labeled amount of ciprofloxacin while BP specifies that the content should not be less than $90 \%$ and not more than $1.0 \%$.

Although the uniformity of weight does serve as a pointer to good manufacturing practice (GMP) as well as amount of the active pharmaceutical ingredients, especially for reproducibility of the product which is very essential for mass production of any product.

The average weight of the four tested tablets products is . $\mathrm{V}^{9} \mathrm{mg}$, the lowest and highest weight are $\cdot$. mg (Ceproz) respectively, while the deviation from average weight for all product is not more than $1.0 \%$. Therefore, all the four brands tested in this study complied with the compendia specification for uniformity of weight which states that for tablets weighing more than $r r \leqslant \mathrm{mg}$, weight of not more than $r$ tablets should not differ from the average weight by more than 0 $\%$.

The tablets hardness was measured as kilogram per $\mathrm{cm}^{r}$ for the four products as another useful parameter to assess the biopharmaceutical properties of tablets. The average hardness test for total products is 17.) $\mathrm{kg} / \mathrm{cm}$, the lowest ( Ceproz, softest) and highest (Bactiflox, hardest) values are $1 \leqslant .9$ and 11.1 respectively.

Normally, a force of about $\varepsilon \mathrm{kg}$ is the minimum requirement for satisfactory tablets. ${ }^{17}$ Therefore the tablets of all products were satisfactory for hardness.

The disintegration times for the following Tyflox, Ceproz and Dr.Reddy's products are $\leq . Y_{0}, 0.1$ and $\leqslant .0$ minutes respectively and their mean is $\{.7$ which is significantly varied from the average of disintegration time of the fourth product ( $A . \vee$ minutes) namely Bactiflox.

Such high disintegration time for Bactiflox product also shows highest value of tablet hardness.

Overall, the four products have disintegration times less than 10 minutes and this complied with the specifications for oral tablets, where BP and USP specification for uncoated tablets and film coated tablets should be 10 and $r$. minutes respectively. Disintegration time is very important since this time could be directly related to dissolution time and subsequently bioavailability of a product.

In many conditions, biological assay of antibiotics is very important in the evaluation of antibacterial products especially for nonsynthetics and semi-synthetics agents.

The size of inhibition zone is the classical approach to assay the activity of antibiotics. In our study, the result shows that all these brands have the same activity in vitro in term of inhibition zone.

In conclusion, this study shows that the four products of ciprofloxacin contain approximately the same amount of a drug and show the same extent of activity as antibacterial agents with the similar hardness of tablets.

However, there is only one product with relatively slow disintegration rate and this may affect the rate of bioavailability but most probably will not affect the extent of bioavailability since the disintegration time still within the requirement of BP or USP for oral tablets.

Finally, post-marketing in vitro bioequivalence studies are essential and important as much as post-marketing studies for adverse drug reactions for new and old drugs. Also such studies may be more important in developing countries where counterfeit and substandard drugs have become a major challenge to health care services.

\section{References}

I.Khan MK, Khan MF. Comparative Bioequivalence and Pharmacokinetics of Ciprofloxacin in healthy male subjects. Pak. J. Phar. Sci. $r \ldots 9 ; r r(1): 1-Y$.

r.Chambers HF, Jawetz E. Sulfonamides, Trimethoprim, Quinolones. In: Katzung BG. Basic and clinical Pharmacology. 9th edition r.. \&, pp.VVT-VAr.

r. Bennett PN, Brown MJ. Clinical Pharmacology. 9th edition $r . . r$, Churchill Livingstone. pp. rrr r r.

$\varepsilon$. World Health Organization. WHO medicines strategy; countries at the core $r \ldots \varepsilon_{-}$ r.. $\vee, Y \cdots \varepsilon, \uparrow$.

- Ngwuluk NC, lawal K, Olorunfemi PO, Ochekpe NA. Post-market in vitro bioequivalence study of six brands of 
ciprofloxacin tablets/caplets.Sci. Res. Essay

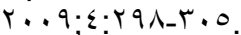

7. Adegbolagun OA, Jegede OJ, Olaniyi AA. Chemical equivalence studies on four brands of metronidazole tablets. Nig J Pharm Res. r...r; (April-Sept): $\vee$ I -V $\varepsilon$.

$\checkmark$. Barone JA, Lordi NG, Byerly WG, Colaizzi JL. Comparative dissolution performance of internationally available piroxicam products.

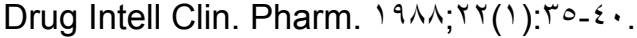

$\wedge$. Mus'ab MK, Imad AT, Al-jammas EA. Bioequivalence study of four carbamazepine generic tablets. Irq J Pharm r..r; r: l $_{-} r$ r.

१. Adegbolagun OA, Olalade OA, Osumah SE. Comparative evaluation of the biopharmaceutical and chemical equivalence of some commercially available brands of ciprofloxacin hydrochloride tablets. Trop J Pharm Res $r \ldots v ; \tau$ : $\vee r v-v \leqslant 0$.

1.. Olaniyi AA, Babalola CP, Oladeinde FO, Adegoke AO. Towards better Quality Assurance of Drugs: Proceedings of $\varepsilon$ th National workshop, Department of Pharmaceutical Chemistry, University of

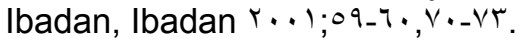

11. British Pharmacopoeia. Version 11. Vol. I and II. Medicinal and pharmaceutical substances r...V:rq

ir. Allen LV, Popovich NG, Ansel HC. Ansel's pharmaceutical dosage forms and drug delivery system. In: Lippincott Williams and Wilkins, Philadelphia 9th edition r. .

1r. National Committee for Clinical Laboratory Standards. Methods for dilution antimicrobial susceptibility tests for bacteria that grow aerobically approved standard. Tth edition

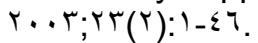

I . Frei J, Heuck C, Riesen W, Lang H, Hill PG, El-Nageh MM, Pollar L. Production of basic Diagnostic Laboratory Reagents. WHO regional Publications. Eastern Mediterranean Series, Alexandria. Egypt, 1990.

10. Forbes BA, Sabm DF, Weissfeld AS. Bailey and Scott's. Diagnostic Microbiology. 1.th edition, Mosby. Inc., USA, 1991.

17. The United State Pharmacopoeia. USP r.NF $Y_{0}$, the official compendia of standards r.. V: 1v00_lvo9. 